\title{
English as Cultural Capital: EFL Teachers' Perceptions: A Cross-Cultural Study
}

\author{
Akhtar Hassan Malik ${ }^{1}, \&$ Anes E. Abdelrahim Mohamed ${ }^{2}$ \\ University of Toronto ${ }^{1}$ \\ University of Tehran ${ }^{2}$ \\ Doi:10.5296/jsr.v5i2.6413ＵRL: http://dx.doi.org/10.5296/jsr.v5i2.6413
}

\begin{abstract}
This qualitative and cross-cultural research study looked into the ways in which English language has come to be seen as associated with symbolic values that can be considered as a form of cultural capital. This research uses Pierre Bourdieu's theory of cultural reproduction as its theoretical framework. The participants of the study were 25 EFL teachers teaching in the Sultanate of Oman where the study was conducted as we were working as faculty members. Audio-recorded and open-ended interviews constituted the main data collection method. The main and most important finding of this study is that English language is used to reproduce social inequality and this is largely due to the fact that it has been fetishized.
\end{abstract}

Keywords: English, Cultural, Capital, EFL Teachers, Perception

\section{Introduction}

"The real political task in a society such as ours is to criticize the workings of institutions that appear to be both neutral and independent, to criticize and attack them in such a manner that the political violence that has always exercised itself obscurely through them will be unmasked, so that one can fight against them." Michel Foucault

English Language Teaching (ELT) operates on a set of problematic but often unexamined assumptions that has far-reaching social, economic, and political implications. Even though many of these assumptions have been challenged by critical educators, the way in which English language is used as a form of capital to reproduce social inequality has received scant attention. In keeping with the spirit of critical inquiry, this paper turns a critical lens on how English learning process is comparable to the process of accumulating capital. Capital is usually the source that provides access to scarce rewards, is subject to monopolization, and, under certain conditions, may be transmitted from one generation to the next (Lareau\&Weininger, 2003, p. 567). It is the investment with certain expected returns. Therefore, it is vital to look into how English has been fetishized in the sense of having highly sought after symbolic value that translates into social prestige. And, to what extent it has a potential to consolidate social inequalities and reproduce existing socioeconomic class 
structure in a society. Besides, in this paper we also intend to raise the problem of the Hegemony of English by discussing two aspects of it, i.e., neocolonialism and globalism. To properly understand such political implications of English language teaching and learning, this paper has drawn insight from Pierre Bourdieu's cultural reproduction theory, and has examined English as Foreign Language (EFL) teacher's perspectives about the value and economic rewards of knowledge and competency of English in providing them and their students with the advantages in the global job markets.

It is beyond question that English is the de facto international language of communication today. It has become the dominant global language of entertainment, education, business, politics and world diplomacy. A number of linguists have reported on the global spread of English, indicating its dominant status and the most prevalent language of the current age. For instance, Ammon (1992) argues that the dominance of English can be understood by the following statistics: (1) English has the greatest number of speakers reaching just over 1.5 billion people; (2) English is designated as an official language of as many as 62 nations; (3) English is the most dominant language in scientific communication with $70-80 \%$ of academic publications being published in it; (4) English is the de facto official and working language in most international organizations; (5) English is the most taught foreign language across the world. Likewise, Faltis (2006), Yan Guo\& Beckett (2007) indicate that English is the first language of over 400-million people in the U.S. Britain , Canada and other Commonwealth countries. More than one billion people speak English as their second or foreign language. Most of these second or foreign-language speakers of English include millions of immigrant students who study in the educational institutions of Western advanced countries. About a billion others in the rest of the world speak English as a Foreign Language (EFL). The estimated users and learners of English in China and India alone number greater than 533 million, which is more than those in the United States, the UK and Canada put together. Cooke (1988) uses the metaphor of "Trojan Horse" to describe the hidden consequences of the global spread of English. It is initially welcomed in a country but subsequently raises concerns, as it dominates the native languages and cultures. Cooke has built this metaphor on the historical story of giant wooden horse, which concealed Greek soldiers who wanted to invade Troy. Similarly, the Trojan (a well-known computer virus) conceals itself in the software programming and destroys the original data. Canararajah (1999) argues that Cooke's metaphor is valid as it suggests that colonialism and class interests have threatened indigenous languages, and act as a gatekeeper to economic opportunities and advancement. However, there is an inner conflict in the learning of English since it may carry unwanted ideologies and cultures with it, just like a Trojan horse. Owing to these circumstances, we believe that teaching and learning of English language should profoundly be examined as a problem of linguistic hegemony and an important cultural capital that may have a potential to determine the patterns of social mobility or a tool for social reproduction.

\section{Theoretical Framework}

This research has employed Pierre Bourdieu's theory of cultural reproduction as a framework. However, in contrast to the way in which theoretical frameworks are often operationalized, we do not intend to imply a rigid and a priori paradigm or a set of presumed postulates to 
guide the research towards pre-set conclusions. Instead, although our framework does provide foundational principles and epistemic boundaries, it allows conceptual constructs to develop through the process of analysis of empirical data. In essence, this is an exploratory study and aims to elicit the participants' responses.

Bourdieu draws on Weber's discourse of exclusionary processes and Durkheim's premise of social classification to develop a theoretical framework to explain the influence of cultural capital on social privilege and individual outcomes (Lamont and Lareau, 1987:158). DiMaggio (1982) argues that Bourdieu's concept of cultural capital is an institutionalized way of widely shared, high status cultural signals such as dispositions, choices and preferences, formal knowledge, behaviors, goods and credentials used for social inclusion and exclusion. Thus, the notion of culture as a capital indicates that it can be saved, invested, and used to obtain other resources (Kingston, 2001: 89). This is an important aspect of the theory in its operationalization and application to the measurement of individual success in various fields. Lamont and Lareau(1987) argue that the strength of the theory lies in its structural nature, while still allowing room for personal agency. For example, while it is institutional structure that develops and perpetuates high-culture, the theory allows for individual variations in how individuals use their cultural capital.

Bourdieu applied his theory primarily to schools, which he viewed to be the institution with the most significant influence in perpetuating the relationship between class and culture (Kingston, 89). Evidence has shown that socially privileged children generally perform better academically and go further in their education. Because education is seen as the predominant pathway to economic success, the importance of cultural capital should not be overlooked. One of Pierre Bourdieu's main arguments was that schools are not neutral settings, created to provide equal opportunities for its students, but are instead perpetuators of social structure and class relations.

\section{Methodology}

This study has employed a qualitative research method, and engaged 25 EFL teachers in open-ended and semi-structured interviews. The participants were carefully picked from a list of volunteers. We preferred teachers who had more than 5-years of teaching experience in different contexts and at international level. We intentionally picked teachers from different nationalities with an idea that it will provide an in-depth as well as comparative understanding of the issue in hand. Every interview began with questions to obtain demographic information of the participants, such as, family economic background, country of birth, mother-tongue, additional languages known, highest level of education completed, employment status, and the contexts where mostly the teaching experience was accomplished, etc. It followed an in-depth discussion to understand the EFL teacher's perceptions about their knowledge of English as a capital, their privileged (or unprivileged) position to convert it into economic capital, and their expectations from the students. Each interview lasted for at least one to one and half hours. A follow up interview was then conducted with each participant to obtain further information on areas which remained unexplained or could not be completely explained. It provided an opportunity to the participants to add whatever they deemed relevant. Data for this study were collected between October 2013 and May 2014. It 
is worth mentioning that this study was conducted in the Sultanate of Oman, where we worked as faculty members. However, for this research we picked participants from three different universities. To pick suitable participants, we sought help from friends, university administrators, and educational bureaucracy in Oman. Most importantly, in order to protect the identity of participants, we have used the pseudonyms of all participants in this paper.

\section{DISCUSSION}

\section{English as Cultural Capital}

Cultural capital is the "instruments for the appropriation of symbolic wealth socially designated as worthy of being sought and possessed" (Bourdieu, 1986, p 73), such as social roles, language competency and refinement, general cultural background, knowledge and skills (DeMarrais\&LeCompte, 1998, p. 15). My participants' narratives generally reveal that knowledge and skills to teach English language have secured for them symbolic meaning and marketable value that are in high demand in many societies, including those of Asia and Middle-East. They believe that due to colonialism, neocolonialism, capitalism, migration and immigration, English has ultimately become the language of all. That is, it is no longer the language of white people of British origin. People from all races and cultures can be native or advanced speakers of English. Therefore, knowledge of English has served as a powerful tool for personal development and advancement, and fluency constitutes a huge step forward in many individual's struggles for self-sufficiency and success. Proficiency in English has become something of a commodity, valuable because of its utility as a basic skill of modern-day life as well as for its image as a form of cultural capital. Almost all those I interviewed cited better economic rewards as the prime reasons for their decision to study English. For instance, Dr. Sharma (an Indian scholar) says, "For me English is associated with better job opportunities..." Hence, he made a conscious decision to get higher education from a reputed British university, and spent over 35 lack Indian rupees to earn his $\mathrm{PhD}$ in English with a notion that proficiency in this language and British accent will help him to get better job opportunities in life. Now he is satisfied that his better planning has paid off. He says, "During 40 years of my teaching experience wherever I went, say for instance, in India, Middle East or even in England, I always got better jobs because I had capability and fluency in English as well as British accent which I mastered after a continuous struggle and hard work" Therefore, for Dr. Sharma both linguistic proficiency and an ability to speak the standard accent are the integral components of linguistic and cultural capital which greatly helped him to gain financial benefits. Likewise, Myrna (an American teacher) argues, "English is the language of money...so I learned it to make money because for many people this is way to go ahead." For Michelle (an American teacher) English is the language of "power" and a mark of superiority. She argues, "It is a reality of the current age of neoliberalism and capitalism that competency in English provides an edge in getting better job opportunities." Therefore, she purposely opted to study English language teaching as a major, and then enrolled herself in the teaching college to obtain B.Ed. with the idea that English teachers can get better employment opportunities in the global markets. Forrest (an Australian teacher) explains that learning English and developing confidence and skill with the use of the language presents individuals with an important range of career advantages. Employers seek 
people that have a strong command of the language and, in professional capacities, the demand for those who know and can use English is certain to continue and grow. Therefore, "I intentionally learned English teaching skills to get better job opportunities in the academia of the world." Dr. Davis (another Indian scholar) asserts, "To be competitive at workplace and in the global job markets, one requires the cultural capital none other than competency and fluency in English as well as an ability to effectively teach it." For Davis the western accent, which can be British, American or Australian, is also an important virtue to compete for better positions. John (an American scholar) argues, "In the current age of globalization ... a nearly universal ideology manifests itself in the belief that cultural capital in the form of English competence is needed for job opportunities, technological advancement, and even national progress."

The above-mentioned perspectives indicate that English competency and pedagogical skills associated with it are a cultural capital that have symbolic values, and are greatly esteemed in many developing societies. Friedman (2003) argues that the social prestige of English knowledge is due to globalization trend. Therefore, it appears that people from different territories and across cultures are ready to invest money, time and effort to gain this cultural capital (in the form of academic credentials or qualification/standard accent, etc.) with perceived expectations of converting it into economic capital (better job placements). However, English generates new dimensions of social and educational inequality because of unequal access to financial rewards. Individual from upper and middle-classes are more likely to get education in elite English-medium schools which are expensive and provide better education and skills to communicate as well as to teach English. These individuals also tend to enroll themselves in elite schools of English speaking countries in order to further enhance their linguistic capabilities. In this study Dr. Sharma and Dr. Davis employed this strategy which, undoubtedly, helped them to obtain immediate social and financial returns. In sum, improving English proficiency as a capital through better education leads to social mobility. However, those who belong to working and impoverished classes with scarce family economic resources have few options to accumulate such linguistic capital and to thereby achieve social mobility.

\section{Hegemony and Dominance of English as Neocolonialism}

Evidently, after its wide-ranging global dominance, English language has become neocolonialist and hegemonic. It creates the structures of linguistic inequality and discrimination between speakers of English and speakers of other languages and exerts an indirect rule over many aspects of their lives. Tsuda (1996) argues that the dominance of English language causes serious consequences which include: (1) linguistic and communicative inequality to a great disadvantage of the speakers of languages other than English; (2) discrimination against non-English-speaking people and those who are not proficient in English; and (3) colonization of the consciousness of the non-English-speakers, causing them to develop linguistic, cultural, and psychological dependency upon, and identification with, the English, its culture and people. Tsuda further says that in a situation where English dominates communication, the non-English-speaking people are inevitably disadvantaged. They become mute and deaf, and therefore prevented from fully participating 
in communication. Canagarajah (2005), too, supports this discourse and argues that English as a dominant language worldwide is forcing an unfamiliar pedagogical and social culture onto its learners; both linguistically and politically, by putting them in danger of losing their first languages, cultures and identities, and contributing to the devaluation of the local knowledge and cultures. Pennycook (1998) draws our attention towards a close relationship between language and power, and argues that the global spread of English is not only a product of colonialism but also the most potent instrument of cultural control. Phillipson terms the spread of English as "linguistic imperialism" and argues that the "dominance of English is asserted and maintained by the establishment and continuous reconstitution of structural and cultural inequalities between English and other languages" (Phillipson, 1992: p. 47).

Hegemony relies on the development of ideological structures which the minority groups will support, hegemonic forces are predominantly non-coercive and are, therefore, useful markers that may illuminate the process by which the dominant ideas in a society are internalized and thus authenticate political legitimization. Thus linguistic hegemony is asserted in multiple ways, for instance, as Kaplan (1993) explains that international scientific collaboration is increasingly dominated by English. As a further example, linguistic hegemony exerts and legitimates power by presenting the dominant language as an instrument, or tool to be used by those who acquire it in whatever way they choose. This is an exertion of hegemonic control because the 'selling' of English appears to be politically and socially neutralized, when in fact it is clearly not the case. Thus, learning of English is presented as a 'technical instrument (like a computer), not a world order' (Phillipson, 1992: 287). To this end, English hegemony is exerted. English as the unquestioned dominant language of usefulness is legitimated. Daily forms of linguistic hegemony include using the media, institutions and social relationships to associate linguistic minorities with inferiority, lower self-esteem, and belittlement yet, to conversely present positive associations with the dominant language and culture. In discussing linguistic hegemony of English, Phillipson (1992) states:

The top language benefits through the image-making of the ads of transnational corporations and the connotations of English with success and hedonism. These symbols are reinforced by an ideology that glorifies the dominant language and serves to stigmatize others, this hierarchy being rationalized and internalized as normal and natural, rather than as expression of hegemonic values and interests (p. 40).

The results of successful linguistic hegemony are often language shift from the minority language to the majority language and, ultimately, language loss. In this context, it will be interesting to examine how individuals, consciously and unconsciously, strive to obtain perfection in English and its different aspects such as fluency/standard accent, etc. How native speakers are rewarded in the international academic job market? And, how English teachers help their students to internalize the hegemony of English? Next sections will explore these important aspects. 


\section{Accent as Capital}

The inequality and neocolonialism transpire in different ways in different contexts. As English has spread to various corners of the world, the demand for native English-speaking teachers from advanced western countries also increased. Likewise, standard 'accent' became popular among the recruiters who control academic employments. Such kinds of discriminative preferences opened the world's job markets to apparently "gifted asset" of native accent, white skin, and western names of the already richest countries. The services of these teachers are expensive and are affordable only to the children of political and financial elite whose investment in education brings them greater political and financial power. Those who cannot afford the expensive services of native English-speaking teachers resort to the service of non-native speakers with a high proficiency of English language. Lippi-Green (1997) argues that in spite of widespread accent variation, discrimination based on accent "can be found everywhere in our daily lives" (p.73). My participants, too, conclude that discriminative practices based on accent are very much part and parcel of international academic world. Asian and African accents are generally ridiculed, while American or European accents are respected and rewarded. For instance, Dr. Johnson (a PhD scholar from Sudan) explains that on numerous occasions he was declined appointment during the interviews solely because of his African accent. He argues that he never thought of his native accent as a communicative disorder any more than he thought of his skin color as a physical disorder. His accent, like his skin color, is a part of who he is and a part of his identity. Dr. Johnson, despite such discriminatory practices never tried to modify his accent as it is to modify his identity. Therefore, he had to accept regular rejections from being hired. Likewise, while pointing to the fact that accent acts in part as a marker of race, Dr. Vino (a Sri Lankan scholar) maintains that her accents mostly evoked negative remarks from recruiters. She says, "I speak with an Indian, or more precisely Tamil, accent because my mother tongue is Tamil." Therefore, she had to swallow the bitter pills when seeing the preference of white candidates over her; in spite of the fact that they had reasonably lesser qualifications and work experience than her. To increase his job opportunities, another participant from Pakistan (Mr. Jahangir) sought to modify his accent by taking "accent therapy" in England. He said that he had to participate in 55-minute therapy sessions conducted thrice weekly for approximately three months in an "accent modification clinic." However, such sessions couldn't do much due to biological reasons. The natural biological processes of the loss of neuroplasticity (language learning ability of brain) and the onset of lateralization (loss of the complex cognitive activity of language development due to puberty) appear to occur at the same time-around puberty. It is during this time that the innate ability to acquire language(s) declines considerably. Scovel (1988) points out that the emergence of foreign accents arises at the same time that lateralization of cognitive, linguistic, and perceptual functions appears to be completed in the human brain, the same time that neuroplasticity appears to terminate. This explains why children are considered biologically predisposed to be better language learners than adults. Conversely, my native speaker participants perceive their western accent as an asset and capital that provides them with a clear advantage in the job market. Most of them claim that their "better" speaking abilities and styles provide them confidence to compete against nonnative-speaker candidates. They argue that the advertisements which 
clearly specify that "only the native speakers can apply for this teaching position" are a blessing in disguise as they already disqualify many nonnative speaker candidates who may have better qualifications. Such kind of approach makes their life easy. However, such practices greatly annoy the nonnative speakers as they find them discriminatory as some races are unduly given advantage. They demand for an open competition than just doing selections or rejections based on candidates' race and background. Such kinds of practices also create a misconception that teaching of English is better carried out by native English speaking teachers. They also have a potential to influence the perceptions of nonnative English-speaking teachers and, by extension, non-native English speaking students, who internalize misconception of the idealized speaker of English. Such misconception and internalization often result in the formation of discriminative and racist attitudes.

\section{White-Skin-Color and Western Names as Capital}

Not only are applicants for English teaching jobs screened for their accent, but also their skin pigmentations as well as names seem to carry considerable weight with recruiters and employers. For instance, Dr. Anes told his colleague from the US about vacant positions at a university in Oman. While she has MA and Dr. Anes has a $\mathrm{PhD}$ and publications, the university opted for the white American woman. Interestingly, the university did not even have a proper interview with her. It was a ten-minute phone conversation and she was accepted. All the university needed was to take a look at her picture. In fact, she was asked to send her recent photo to make sure that she would fit the stereotype of a white person. Other participants also expressed the same anxiety of being left out due to their skin color or non-western names. For instance, Dr. Gandhi explains that mostly his job seeking efforts, despite having a $\mathrm{PhD}$ degree from Canada, could not earn him interview calls due to his Indian skin and name. Whenever he applied for the job with his white friends, they received invitation for an interview and Dr. Gandhi was grossly ignored. He argues that the fair-skin syndrome is deeply seated in the minds of most recruiters. They unduly believe that white teachers have better English teaching skills than non-whites. Likewise, Dr. Davis shares his experience of attending some job fairs in the Middle East. He concludes that every time most of his white competitors were preferred over him despite the fact that he had a $\mathrm{PhD}$ degree and most white candidates had considerably lesser qualifications. White-skinned participants are quite familiar with this kind of unjust preference. For instance, Michelle says, "It's a learned cultural bias, plain and simple" and argues that 'colorism' can be found all over the world in which wealth and social status are determined by skin color. Throughout the numerous societies across the world, the lightest-skinned peoples have the highest social status, followed by the brown-skinned, and finally the black-skinned who are at the bottom of the social hierarchy. This form of prejudice often results in reduced opportunities for those who are discriminated against on the basis of skin color. Likewise, John explains that racial preferences aren't a celebratory, untouchable birthright transmitted to you in the womb, and fair treatment with teachers across the race and color is the need of time. Therefore, it appears that hiring white teachers seems to be an all-pervasive business-driven practice as it attracts more customers (i.e. students) by pandering to their prejudices.

\section{Reproduction of English Language Hegemony during Teaching Practices}


An individual's proficiency in a language refers to the degree to which he or she is able to use the language. Language is used for various purposes. In education, we can categorize the use of language into two dimensions: the social dimension and the academic dimension (Cummins, 1981). The skills necessary for social interactions are usually the listening comprehension and speaking abilities sufficient to understand and respond to social communications. The language learning can be compared to an iceberg. The portion that is visible on the surface, usually the social dimension, is only a fraction of the total iceberg. In order to use a language in academic work, the speaker must have an extensive foundation of the language. This foundation is acquired through rigorous efforts on the part of learners over an extensive period of time and in the settings designed to build that foundation. The academic dimension can be compared to the portion of an iceberg that is not visible, because it is under the surface of the ocean. My participants being totally aware of the cultural capital dimension of English purposely provide educational experiences to their students during the class work which are associated with both social and academic dimensions. They not only focus their class work to develop high levels of linguistic capabilities among students but also abilities to analyze and reflect. Their ultimate goal is to equip their students with enough linguistic skills so that they become able to reap maximum benefits in national and international job markets. For instance, Dr. Sharma explains that he always allows his students to offer ideas and feedback about what goes on during the class work. He likes to share his power and encourages his student's input into many areas of class-work. Likewise, Joanne (an American teacher) provides the learning settings where her students can use higher levels of cognitive processes by comparing and contrasting their views with one another in small groups in order to come to a consensus and together synthesize information to present it to the larger group. She believes that her class work strategies help her students to gain enough practice in the use of the language necessary to carry on higher levels of negotiations. She tends to provide activities which are "more varied, and purposeful, and foster the higher levels of linguistic proficiency among students." Therefore, both Dr. Sharma and Joanne, through carefully designed classroom activities, consciously encourage their students to acquire enough cultural capital in the form of English language competency as well as higher levels of cognitive capabilities which they can use in leadership roles in future life. Other teachers, too, believe in collaborative learning and plan small group activities where students work on common tasks to clarify and negotiate meaning with one another which, as McCloskey, (1990) argues, results in complex language input, including low-level input (repetition of information), middle-level input (stating of new information), and high-level input (integrating information and creating rationales for its use). All of these types of language input are crucial to second language acquisition. Therefore, Dr. Davis believes that by employing the procedures of participatory learning in his classes he, in facts, empowers his students to attain higher levels of linguistic proficiency as well as cognitive capabilities. He encourages his students to make decisions about what and how they want to learn. This way he tends to increase their intrinsic motivation as well as develop decision making capabilities. However, Jacquie (a teacher from South Africa) argues that every EFL teacher must understand how culture impacts learning in their classroom. It is vital to link new information to the student's prior knowledge. To achieve this end, every teacher needs to consider what schema students bring into the classroom and then link instruction to the students' personal, 
social and world experiences. Teachers also need to find out what their students do not know.

The above perspectives indicate that EFL teachers consciously teach English as a dominant language of the world. However, in doing so the teachers are indirectly helping the "Colonization of Consciousness" of their students. Ngugi(1981) argues that the linguistic domination leads to mental control. This implies that the global dominance of English today is to lead to the control of the mind of the global population by the speakers of English, their nations and governments. Ngugi further says that mental control is made possible by a combination of the "destruction or the deliberate undervaluing of a people's culture and the conscious elevation of the language of the colonizer" (p. 160). In the face of this mental controlling, the colonized/dominated usually are coerced into complying with the force of mental controlling, which facilitates the execution of the colonization of the mind. In short, the dominated are led to identify with the dominator, and glorify the dominator's language while devaluing their own language and to an English-centered one; namely, the colonization of people's mind and the conscious devaluing of their own language.

\section{Conclusion}

The inescapable conclusion of this critical inquiry is that there is more to English language than just communication. Like almost every practice under capitalism, the way English has spread reveals uneven power structure that has given impetus to its rapid global spread. In turn, this uneven power structure has become institutionalized in certain unquestioned assumptions and practices that ultimately maintain and perpetuate the very structure that has given rise to them in the first place. Since it is the language of the dominant power, it naturally follows that it poses serious threat to the languages of the dominated.

Furthermore, as capitalism is inherently indifferent to use values, everything is perceived in terms of its exchange value. It is in this sense that English has come to be associated with what it can be exchanged for: cultural capital, better job opportunities, prestige, progress, modernity, etc.... It is this fetishization of English which has rendered it a powerful tool in the reproduction of social and economic inequality on multiple levels. It is not a coincidence that ELT has become a highly profitable industry controlled by the center (US, UK, Australia) rather than the periphery in this uneven power relation. As a consequence, the underlying assumptions by which ELT is driven benefit the center to the exclusion of the periphery. This is the political violence alluded to in the quote at the beginning of this paper. It is a form of structural violence because it legitimizes exclusionary and discriminatory practices which end up depriving people from the periphery of certain job opportunities. It is also a form of political violence when the commodification of English leads to the creation and perpetuation of class privileges. As learning English is an expensive process, only upper and middle classes from the periphery can afford it. As a result, poor and working people are denied the opportunity to cash in on the cultural capital of English language.

Having laid bare the uneven power structure behind the hegemony and commodification of English, what form should the fight for a just society take? Should the oppressed strive to pick up the cultural capital (English) of the oppressor so as to have access to better job opportunities? The great Brazilian educator, Paulo Freire, argues against such a pedagogy: 


\section{Macrothink}

"No pedagogy which is truly liberating can remain distant from the oppressed by treating them as unfortunates and by presenting for their emulation models from among the oppressors. The oppressed must be their own example in the struggle for their redemption (p. 54)."

Internalizing the values of the oppressed will only deepen the oppression. It is our belief that it is not through the cultural capital of the dominant group that the dominated can liberate themselves. Since English has become a lingua franca, the oppressed should appropriate it for their own use after stripping away its fetishization. This would be the best strategy to combat English as a cultural capital.

\section{References}

Ammon,U.(1992). The Structures of the Dominance of English, Tokyo:Sangensha.

Bourdieu, P. (1986). The forms of capital.In J. Richardson (Edš .), Handbook of theory and research for the sociology of education (pp. 241-258). New York: Greenwood Press.

Johnson, A. (2009). The Rise of English: The Language of Globalization in China and the European Union, Macalester International Vol. 22.http://digitalcommons.macalester.edu/cgi/viewcontent.cgi article=1447\&context=macintl

Cummins, J. (1981) "The Role of Primary Language Development in Promoting Educational Success for Language Minority Students."Schooling and Language Minority Students: A Theoretical Framework. Los Angeles: Evaluation, Dissemination, and Assessment Center, California State University, USA.

DeMarrais, K. B., \&LeCompte, M. D. (1998). The way schools work : A sociological analysis of education. New York: Addison-Wesley Longman.

DiMaggio, P (1982). Cultural Capital and School Success: The Impact of Status Culture Participation on the Grades of U.S. High School Students." American Sociological Review, Vol. 47, PP, 189-201.

Erickson, Bonnie H. "Culture, class, and connections." American Journal of Sociology 102 (1996): 217-251.

Freire, P. (1970). Pedagogy of the oppressed. New York: Seabury Press.

Kingston, Paul W. "The unfulfilled promise of cultural capital Theory." Sociology of Education 74 (2001): 88-99.

Lareau, A (1987). Social class differences in family-school Relationship: the importance of cultural capital. Sociology of Education, Vol.60, pp.73-85. 


\section{Macrothink}

Journal of Sociological Research

ISSN 1948-5468 2014, Vol. 5, No.2

Lareau, A., \&Weininger, E. B. (2003). Cultural capital in educational research: A critical assessment. Theory and Society, 32(5/6), 567-606.

Lippi-Green.R. (1997). English with an Accent: Language, Ideology, and Discrimination in the

United States. New York: Routledge.

McCloskey, M.L. (1990). Integrated Language Teaching Strategies. Atlanta, GA: Educo Press, pp. 4-5.

NgugiwaThiongo(1981). Decolinizing the Mind: The politics of language in African Literature. London: James Carey.

Pennycook,A.(1994). Cultural Politics of English as an International Language. London: Longman.

Phillipson,R.(1992). Linguistic Imperialism. London: Oxford University Press.

Scovel, T. (1988). A Time to Speak: A Psycholinguistic Inquiry into the Critical Period for Human Speech. New York: Newbury House.

Roscigno, Vincent J., and James W. Ainsworth-Darnell. "Race, Cultural Capital, and Educational Resources: Persistent Inequalities and Achievement Returns." Sociology of Efucation 72 (1999): 158-178.

Throsby, D (1999). "Cultural Capital," Journal of Cultural Economics Vol. 23: pp. 3-12. Tsuda,Y.(1996). The Invading English, the Counterattacking Japanese. Tokyo:PHP. Yosso, Tara J. (2005). "Whose culture has capital? A critical race theory discussion of community cultural wealth.” Race Ethnicity and Education Vol. 8: pp. 69-91. 